\title{
El joven Winston y El instante más oscuro: Winston Churchill como líder político en una Europa cambiante
}

\section{Young Winston and Darkest Hour: Winston Churchill as a Political Leader in a Changing Europe}

\author{
Marta Frago \\ Universidad de Navarra, España \\ mfrago@unav.es \\ https://orcid.org/oooo-0002-6179-0558
}

Daniel Sierra

Universidad de Navarra, España

dsierrav@unav.es

\section{Resumen:}

Las películas El joven Winston (Young Winston, R. Attenborough, 1972) y El instante más oscuro (Darkest Hour, J. Wright, 2017) se estrenan en dos momentos críticos en Europa y el Reino Unido, vinculados a la revolución del 68 en el primer caso, y al declive político y socioeconómico del mundo occidental, en el segundo. Ambos filmes imprimen una representación positiva de Winston Churchill como líder político. En este artículo se pone en relación al personaje y las cualidades concretas que se subrayan de él con la crisis que acontece en el momento del estreno de cada película. Asimismo se vinculan estos biopics con el momento que atraviesa en cada caso el "sueño europeo": su apogeo y su declive. El análisis concluye que la imagen de Churchill se recorta en cada filme de acuerdo con el patrón de liderazgo más deseado en cada momento histórico.

\begin{abstract}
:
The release of both Young Winston (R. Attenborough, 1972) and Darkest Hour (J. Wright, 2017) coincide with two critical moments in the history of Europe and United Kingdom. The former, in the wake of the 1968 protest movements; the latter, in the midst of the political and socio-economic decline of the Western world. Both films offer a positive portrayal of Winston Churchill as a political leader. In this article, we link the concrete qualities highlighted in Churchill's character with the crisis that was escalating at the time of each release. Besides, we connect the two biopics to the relevant stages of the "European Dream": namely, its peak and its decline. The analysis concludes that in both films Churchill's image is cut out according to the most desired leadership pattern of the related historical time period.
\end{abstract}

Palabras clave: drama biográfico; biopic; cine histórico; Churchill, Winston; narrativas de la crisis; sueño europeo.

Keywords: Biographical dramas; Biopic; Historical Films; Churchill, Winston; Narratives of crisis; European Dream. 


\section{Introducción ${ }^{*}$}

A Winston Churchill se le ha representado en el cine y la televisión en más de sesenta ocasiones y al menos en una docena de ellas como protagonista (Bishop, 2018, p. 8). Estos retratos del político y primer ministro inglés reflejan el carácter icónico que ha adquirido su figura con el paso de los años. Sin ir más lejos, una macro encuesta nacional realizada por la BBC en 2002 lo situó como el mayor líder británico de todos los tiempos ${ }^{1}$. Su liderazgo, no obstante, se extiende a Europa, al ser una figura clave en la reconstrucción del continente a partir de 1945 y un impulsor temprano de la Unión Europea.

El carácter legendario que se ha otorgado a la figura de Winston Churchill en los años posteriores a la Segunda Guerra Mundial constituye el primer punto de partida de este trabajo. Consideramos que sus biografías, y más en concreto las dos películas que analizamos aquí, no sólo representan al hombre histórico sino fundamentalmente al mito construido en torno a él, tan importante para la identidad nacional británica como para Europa occidental. Eljoven Winston (Young Winston, R. Attenborough, 1972) y El instante más oscuro (Darkest Hour, J. Wright, 2017) se han nutrido del imaginario colectivo y a su vez lo han retroalimentado. Tal y como ocurre en las biografías de gobernantes en general, los dos filmes son reconstrucciones de la vida del primer ministro en las que pesan más la imagen, el mensaje y el mito que la precisión histórica y su complejidad (Morgan, 2011, p. 2). Viene a suceder, como expresa Bingham, que quien escribe o filma la vida de alguien famoso, no hace otra cosa que introducirlo en el panteón de la mitología para mostrar de qué manera tiene cabida en él. (2010, p.10).

El segundo punto de partida es la consideración de que estos biopics sobre Churchill recortan e interpretan al primer ministro inglés de acuerdo con los valores sociales que se subrayan más en cada época. Numerosos autores defienden la tesis de que toda biografía trae una actualización de la vida de

\footnotetext{
* Este artículo se ha desarrollado en el marco del Proyecto de Investigación I+D "La crisis del European Dream: hogar, identidad y éxodo en las artes audiovisuales", con referencia HAR2017-85846-R, financiado por el Ministerio de Ciencia e Innovación

${ }^{1}$ Se realizó con la votación de los telespectadores durante el programa de la BBC 100 Greatest Britons.
} 
alguien famoso acorde a los tiempos en que se filma (Toplin 1996, p. 16-19; Vidal 2014, p.4). "At the heart of the biopic is the urge to dramatize actuality", dirá Bingham (2010, p. 253). Y, como defiende Scott, los biopics se construyen de acuerdo con los valores e ideales que están en juego en la época contemporánea correspondiente (2011, p. 161). En general, toda película histórica (donde se inserta el biopic) habla al presente desde el pasado (Champman, p. 1). Lo expresa bien Landy:

History is often invoked as a judgement on present events. The period film work in allegorical fashion to dramatize contemporary reality by making an analogue with the remote past in the interests of continuity, or, conversely, the history may serve as an excuse to be critical where direct discourse may fail (1991, p. $55)$.

El tercer punto de partida está en el hecho de que el biopic político tiende a emerger en tiempos de crisis (Landy, 2001, p. 63; Pennacchia, 2014, p. 33; Frago y Alfonso, 2016, p. 2-3) y este rasgo también es común a las dos películas. Coincide que ambas pertenecen a dos periodos de tiempo convulsos para Europa y el Reino Unido, aunque lo sean por muy distintas razones. El comienzo de la década de los 70, periodo al que pertenece El joven Winston, viene a ser el eco más próximo de la revolución de mayo del 68 en el mundo occidental. Entre otras características, esta revolución se manifesta en una "desconexión completa entre la cultura joven y el resto de la sociedad" (Marwick, 2006, p. 41), un momento en el que se cuestionan los patrones culturales tradicionales. A la vez es una década de crisis económica y política en el Reino Unido, conocida como "Dark Ages”. También la segunda década del siglo XXI en la que se estrena El instante más oscuro puede considerarse una época conflictiva, con el peligro de desmembración de la Unión Europea y una importante desconfianza en la política internacional por parte de los ciudadanos. La amenaza del Brexit y la incertidumbre de sus secuelas impregna la sensibilidad nacional británica y europea.

Con estos tres puntos de partida estudiamos a continuación la representación positiva del liderazgo de Churchill como simbólicamente elocuente y significativa en las dos películas elegidas. Nos interesa examinar en qué 
medida el personaje de Winston Churchill encarna en cada largometraje las virtudes sociales mejor valoradas en la época de su estreno y hasta qué punto resulta una figura representativa del sueño europeo que emerge tras la Segunda Guerra Mundial y se tambalea en nuestros días. Para su análisis tendremos en cuenta tanto el marco histórico en el que es producida cada película como los ángulos desde los que se aborda la personalidad del líder y el modo en que se estructuran y narran las respectivas historias, siguiendo a autores como Rosenstone (2006), Ferro (2008) o Toplin (2002).

\section{1972: la juventud; 2018: la experiencia}

Lo primero que llama la atención al poner en comparación los filmes de Richard Attemborough y Joe Wright es que representan dos periodos distintos de la vida del político inglés. Como ya ocurriera con los consagrados filmes sobre Abraham Lincoln en Estados Unidos: Abraham Lincoln (W. D. Griffith, 1930) y El joven Lincoln (Young Mr. Lincoln, John Ford, 1939), la madurez y la juventud del líder constituyen los dos momentos preferidos por el cine. En lo que se refiere a Winston Churchill, el filme El joven Winston da protagonismo a la infancia y principalmente a la juventud como periodo de preparación y configuración de la personalidad del futuro político. Centran la trama sus aventuras como corresponsal de guerra, escritor y su carrera militar, descritas en la autobiografía My early life ${ }^{2}$ y reseñadas posteriormente en otros textos biográficos ${ }^{3}$. En contraste, El instante más oscuro presenta a un Churchill ya experimentado, que previamente ha sido ministro y sobre quien recaen algunos aciertos, pero también sonados errores como la Batalla de los Dardanelos en 1915 o la entonces reciente Operación Wilfred de 19404. En concreto, la película se centra en los días en que, recién elegido primer

\footnotetext{
2 Escrita por Churchill tras perder las elecciones del Partido Conservador en 1929 y publicada en 1930 por la editorial Thornton Butterworth.

3 Son muchas las biografías escritas sobre Churchill. Destacan, entre otras las de Gilbert, M. (1971), Winston S Churchill: The Challence of War: 1914-1916; S. Haffner (1967), Churchill (Life and Times), y R. Jenkins (2001), Churchill.

4 La Batalla de los Dardanelos en la península turca de Gallípoli en 1915; La Operación Wilfred en abril de 1940, que desemboca en la batalla de Narvik en los fiordos noruegos, donde Gran Bretaña fracasa contra Alemania.
} 
ministro, decide oponerse a Hitler aun pagando el precio de prolongar la guerra contra Alemania y sus aliados. Esta difícil decisión, que resultó determinante para la futura democracia en Europa, lo convierte en líder indiscutible.

Sostenemos que la elección de un Churchill joven en la primera película y un Churchill maduro en la segunda, contraponen promesa y experiencia, optimismo y nostalgia como emblemas de dos épocas diferentes.

\subsection{Eljoven Winston y la revolución del 68}

En lo que se refiere a El joven Winston, la elección de la etapa juvenil de Churchill está directamente relacionada con los movimientos culturales simbólicamente fechados en mayo del 68 y en los que se estrena el filme. La explosión de juventud que supuso este fenómeno cultural produjo una crisis importante, un cambio social profundo a la hora de entender al ser humano, su libertad y sus posibilidades. La juventud pasó a ser considerada la etapa de mayor plenitud vital (Marwick, 2006, p. 44). Para Marín Pedreño, se trató de "la invención de la juventud como sujeto histórico", pues "eso es exactamente lo que ocurrió en las sociedades occidentales y desarrolladas en torno al 68: la constitución de un nuevo sujeto social e histórico que abría una época caracterizada por la hegemonía de lo jovial como paradigma cultural” (2018, p. a434).

Tal y como explica Marwick (2000 y 2006) son diversos los factores demográficos, tecnológicos, ideológicos e institucionales que convergen entre 1958 y 1974 marcando un cambio de época y trayendo una cultura a todas luces juvenil. En primer lugar, hay que considerar el baby boom tras la segunda contienda mundial, que cristaliza en los años 60 con una población principalmente joven. Si a esto sumamos factores como el desarrollo económico al alza y sin graves interrupciones, el consumismo y la adquisición de nuevas comodidades que trae la tecnología, el papel creciente de los mass media, los cambios a veces convulsos en educación, en las relaciones personales y familiares, o la posibilidad de viajar con mayor facilidad y de intercambiar bienes y productos, nos encontramos con una población joven 
que ha crecido con una sensación de seguridad y autoestima sin precedentes (2006, p. 39). Los jóvenes se convierten en protagonistas de un estilo de vida que va penetrando en la sociedad poco a poco. La juventud empieza a dictar su gusto en moda y cultura popular, convirtiéndose el pop/rock o la minifalda en una especie de lenguaje universal. Los eslóganes Changing the World y Having a Good Time se expanden y provocan el deseo de permanecer joven aunque pasen los años. Como se sabe, es también un tiempo donde conviven las protestas juveniles contra la autoridad, la policía y, en general, el establishment; la lucha por los derechos civiles; la práctica de la llamada "liberación sexual"; y el consumo de drogas y alcohol. En definitiva, la revolución del 68 fue "una protesta en el corazón de la sociedad del bienestar, de la abundancia y de la satisfacción... que se sentía insatisfecha” (Pérez López, 2018, p. 104).

El año en que se estrena el filme Young Churchill, por tanto, pertenece a una época de convulsión y crisis por el ahínco con que la juventud trata de desbancar los valores tradicionales y se proyecta hacia la novedad y el cambio. Como se ilustrará más adelante, la personalidad del joven Winston Churchill en la película de Attenborough se dibuja acorde con el optimismo, la determinación y el carácter rebelde y poco convencional que caracteriza a la juventud occidental de los años 70. Especialmente en los episodios sobre sus correrías como soldado y corresponsal en India, Sudán y Sudáfrica, el personaje de Churchill se alinea con el espíritu juvenil de la época y su deseo reformista a nivel social y político. Se vuelve un símbolo de la promesa de futuro.

\subsection{El instante más oscuro y la Europa envejecida del siglo XXI}

El caso de El instante más oscuro es diferente. También en este filme el personaje de Churchill encaja bien en el contexto histórico del espectador del momento. La segunda década del siglo veintiuno es igualmente un tiempo agitado, aunque por diferentes razones. Si en los 70 la crisis apuntaba hacia el futuro que podrían traer los jóvenes rebeldes, en este caso la inestabilidad social, económica y política de una Europa envejecida está asociada a un 
estado de nuevo pesimismo, que según Cerny tiene dificultades de proyectarse hacia el futuro y regresa con cierta nostalgia hacia el pasado (2010, p. 191-203). Así, no es de extrañar que en esta película se rescate al Winston Churchill visionario, aquel que en mayo de 1940 se enfrentara a uno de los momentos más oscuros y difíciles para la Europa del siglo XX. Recién elegido primer ministro, Churchill decide declarar la guerra a Alemania y buscar alianzas internacionales para frenar el ansia expansionista de Hitler. Para ello se ve obligado a resistir la presión de quienes en su propio partido le instan a negociar condiciones de paz con el Führer, como se aprecia en las escenas de la película en que discute con Chamberlain y Halifax. El Churchill de El instante más oscuro ya no es el joven que soñaba con política e hizo lo imposible por convertir sus aspiraciones en realidad. Es, por el contrario, el experimentado político que lo arriesga todo para capear la amenaza que se cierne sobre Gran Bretaña y toda Europa. La imagen, por tanto, es nostálgica y viene a ser una llamada de atención hacia los tiempos presentes. Como comentará la actriz Kristin Scott Thomas durante la promoción del filme: “(En la película) Winston es un personaje apasionado, que hizo mucho durante la guerra, y creo que ahora necesitamos gente así, necesitamos gente entregada, apasionada y con integridad”. (Zurro, 2018).

Conviene recordar que las convulsiones que experimenta el mundo occidental en la fecha de estreno de la película son fruto de un declive cuyo inicio toma como fecha simbólica el 11 de septiembre de 2001. Más allá de la magnitud del atentado terrorista que sufrió Estados Unidos aquel día, el ataque supuso un punto de inflexión en la posición hegemónica de Norteamérica y el bloque occidental en las relaciones internacionales. La inestabilidad económica de los años posteriores tambaleó una sociedad del bienestar que parecía infalible. De un lado, la recesión global del 2008 frena la economía occidental, mientras países asiáticos como China e India se constituyen en mercados emergentes. De otro, la seguridad de los países occidentales se ve amenazada por la acción violenta de grupos terroristas islámicos, especialmente activa desde 2001. Hay que sumar, además, la inseguridad cibernética como efecto adverso que trae la democratización de las nuevas tecnologías. Las redes sociales, sin legislación 
clara ni control real, expanden noticias falsas y se convierten en un potencial instrumento de manipulación masiva. Si a todo ello sumamos la caída de credibilidad de los gobernantes y la irrupción de los llamados "nuevos populismos”, y añadimos el problema que trae la intensificación de los flujos migratorios y la amenaza medioambiental, obtenemos una magnitud de la crisis en la que está envuelta Europa occidental en los últimos años (Stevens and Michelsen, 2010, p. 1-12)

La diferencia de esta convulsión con respecto a la crisis de los 70 estriba en la actitud pesimista que se advierte a nivel social y político. Aquel aire de progreso de los 70 y la actitud juvenil de los protagonistas del 68 tratando de abrir una nueva página de la historia desaparecen en el nuevo milenio. El talante general en 2017 es de desconfianza en el futuro. El tono de advertencia y respeto hacia el día de mañana se hace presente en las protestas sociales y en las cumbres políticas internacionales. Se mira al pasado con melancolía. Los nuevos populismos no son sino la expresión de la crisis que experimenta el sistema democrático liberal, por lo que se proponen retornos hacia totalitarismos ya conocidos en el mundo no democrático (Rodríguez Sáez, 2018). Así pues, en el modo de representar a Churchill en El instante más oscuro se advierte esa añoranza por un líder que en tiempos difíciles supo estar a la altura de las circunstancias. El personaje de esta película es símbolo de otro tipo de inconformismo: el de quien casi en solitario se bate contra la opinión generalizada y los modos de hacer habituales. Churchill adopta una postura casi cerril pero visionaria para no llevar a Gran Bretaña a la ruina moral durante la Segunda Guerra Mundial. Al fin y al cabo, El instante más oscuro muestra al líder político como referente democrático frente a la amenaza del totalitarismo nazi.

\section{Desmontando a Churchill}

Juvenil y rebelde en El joven Winston; Experimentado, visionario y comprometido en El instante más oscuro. La imagen de Churchill en estas dos películas coincide, como hemos visto, con el modelo de líder que mejor 
acompaña a la sociedad del momento. Se profundizará a continuación en la construcción del personaje en cada película con el propósito de fijar cuáles son los rasgos del líder británico que el público de 1972 y de 2018 aplaude inconscientemente.

Antes de tratar cada película por separado, conviene recordar que hay siempre un común denominador en las representaciones fílmicas de Churchill. Hay rasgos físicos y de carácter que se repiten y conforman todo un imaginario colectivo sobre el líder en sus años de madurez. En lo más exterior, su figura corpulenta, la tez blanca y sensible, así como el puro, el whisky y el uso del bombín, que atestiguan las fotografías de la época. En cuanto a sus habilidades y carácter, definen al primer ministro una brillante oratoria, un sentido del humor muy británico, así como excentricidades varias, la tendencia a la depresión y una determinación y coraje sobresalientes. Si bien estas características de su persona puedan haberse exagerado hasta cierto punto en la gran pantalla, sí parece que el auténtico Winston Churchill disponía de un semblante y carácter acordes a lo que han presentado las ficciones. Tanto las biografías históricas como testimonios de coetáneos suyos y sus propias novelas autobiográficas lo corroboran5.

No obstante, el conocimiento completo de quién era Winston Churchill o de cualquier ser humano es una empresa imposible. La biografía más reciente de Andrew Roberts (2018) sugiere un retrato tan poliédrico que pone de manifiesto la incomprensibilidad a la que nos asomamos. No es fácil separar lo que fue Churchill en cada momento de lo que mostró ser en público, al igual que quienes le pintan, fotografían o escriben sobre él no están tampoco exentos de subjetividad.

Es evidente que las representaciones de Churchill en El joven Winston y El instante más oscuro son limitadas. En cada película el modo de ser de Winston Churchill se desprende de las acciones que el personaje lleva a cabo en el

5 Son muy abundantes las fuentes de referencia. La International Churchill Society (ICS) incluye en su web información sobre biografías y documentos alusivos a la vida del político inglés. Cfr. https://winstonchurchill.org. 
transcurso de la trama, que a su vez ocurren en un período concreto de su existencia (la juventud o la madurez). Solo el hecho de determinar qué acciones documentadas de la vida de Winston Churchill se representan en el filme y cuáles no supone un sesgo, el subrayado de algunos aspectos de su personalidad y carácter frente a otros. Pero también habría que considerar el tipo de licencias que toma la ficción con respecto a la vida real de Churchill, pues con frecuencia en estos detalles inventados es donde se revelan principalmente los subrayados.

\subsection{Eljoven Winston}

El diseño del guion de El joven Winston no se parece al que tradicionalmente se imprimía en los biopics históricos de los 40’ y 50’. Carl Foremanº, por entonces un guionista experimentado, lo único que mantiene del biopic clásico es la representación de un largo periodo de la vida del líder (infancia y juventud), pero lo hace con una nueva fórmula. La base del guion es la autobiografía de Churchill My early Life, pero en vez de recurrir exclusivamente al uso de una voz narrativa con flashbacks para destacar y ensamblar algunos episodios de la vida de Churchill, recurre a la interposición de hasta siete voces narrativas. A la voz de un Churchill adulto como narrador, que lee unas memorias como hilo conductor de la historia, se añaden las voces del joven Churchill, de sus dos progenitores y de tres periodistas. El resultado es bizarro y algo irregular, pero esta estructura le permite combinar la acción externa del personaje (que adopta un tono épico y de aventura muy en boga en los años 70) con la atención a la psique del personaje, con claras referencias al legado de Sigmund Freud. A estas características hay que añadir una más, especialmente importante para entender el filme $E l$ joven Winston como representativo de su época. Se trata del carácter de antihéroe que adopta el protagonista, característico del cine de Hollywood de los años 70 (González Requena, 2006). El personaje de Churchill (interpretado por Simon Ward) queda lejos de parecerse al héroe épico clásico, alguien superior al común de

${ }^{6}$ Carl Foreman (Chicago 1914-Beverly Hills 1984), fue un reconocido guionista, autor de películas como El ídolo de barro (Mark Robson, 1949), Sólo ante el peligro (Zinemann, 1952), El puente sobre el rio Kwai (David Lean, 1957) o Los cañones de Navarone (J. Lee Thompson, 1961). 
los mortales por sus hazañas y fortaleza y sobre todo por su superioridad moral y la búsqueda de un bien colectivo. El joven Churchill es retratado de forma ambivalente. Su valentía y hazañas son poco comunes, pero rozan la temeridad. A algunos grandes gestos se suman otros propios de la picaresca. Su motivación está más relacionada con heridas psíquicas de la infancia y juventud que con un acto de servicio al país. En definitiva, se nos muestra a un personaje persiguiendo un bien individual antes que colectivo, un antihéroe tal y como es definido por voces reconocidas (Campbell, 1949; GonzálezRequena, 2006). Tan es así que, en algunos momentos del filme, como sucede en la huida de Churchill de la cárcel de Pretoria, tiene más parecido al papel de rebelde y pícaro que interpretara Robert Redford en Dos hombres y un destino, que al del preocupado Churchill que veremos en el análisis de $E l$ instante más oscuro.

Pero introduzcámonos en la película. Esta abre y finaliza con imágenes históricas de archivo, mostrando a un Winston Churchill triunfante, saludando al pueblo británico el día de la victoria, al término de la II Guerra Mundial. El objetivo de estas imágenes es acercarnos a la gloria futura del personaje y su trascendencia para la historia de Gran Bretaña y del mundo occidental. Se superponen estas imágenes con el inicio de la narración, momento en el que se introduce al joven Winston durante una campaña militar en la India en agosto de 1897. Se presenta como corresponsal de guerra, como un soldado ingenuo, ambicioso e imprudente, que cabalga a lomos de un caballo blanco fácilmente identificable por el enemigo y que busca ante todo reconocimiento y medallas para así ganarse un porvenir en su carrera como político. Una carta de su madre (en off) sirve para trasladar al espectador atrás en el tiempo y hacer un breve recorrido por la dura infancia de Churchill. Ahora es la voz del narrador (Churchill adulto) la que nos transporta al primer internado al que le enviaron sus padres. Queda patente la falta de atención de sus progenitores en su educación, resaltando el propio Churchill que sólo amó y se sintió querido verdaderamente por su niñera Everest, mejor conocida por su apelativo: Womany. 
Tras la salida del internado, dentro del que recibe palizas por parte del profesor hasta enfermar, la trama se centra en el desmoronamiento de la carrera política de su padre, interpretado por Robert Shaw. Este hecho supone un punto de inflexión para la familia de Winston. A la ruina profesional de su padre se une la enfermedad y su progresiva demencia a causa de sífilis. El carácter del pater familas se hace irritante y arisco. En medio de todo, Winston lucha por captar la atención de su padre. La película presenta sucesivas conversaciones del jovencito Churchill con él. En una de ellas le propone ser militar, a lo que el protagonista responde con entusiasmo, sintiendo que por primera vez su padre lo proyecta haciendo algo valioso. La realidad es que está buscándole una salida airosa, preocupado por sus malas calificaciones en la escuela. Desde entonces su padre pone todo su empeño en su preparación para la carrera militar. La decepción llega en otro episodio en el que el joven Winston le comunica que ha aprobado el acceso en tercera convocatoria y entrará en caballería, recibiendo durísimas palabras por parte de su progenitor, que deseaba para él la infantería. Queda así subrayado en la película que Churchill convierte esos años de su vida en un constante esfuerzo por honrar y demostrar a su padre que podía hacer algo bien.

En el periodo posterior del filme, que transcurre entre el fin de la infancia de Winston y su primer intento de acceder a la política a los 23 años, se intercalan tres entrevistas periodísticas a su padre, sir Randolph Churchill; su madre, Lady Randolph; y al propio Winston. Es una fórmula muy poco convencional en la que, a través de las preguntas puntillosas de periodistas y las reacciones molestas de cada uno, el guionista aporta una información supletoria a la voz autobiográfica de Churchill, vinculada a los rumores que corren sobre los miembros de la familia. Son cuestiones claves, con las que el guionista tira de la manta para descubrir algunas realidades que se esconden tras las apariencias y que explican mejor las heridas que pudo recibir Winston durante su infancia y juventud, conformando inevitablemente su personalidad. "El árbol solitario crece más fuerte”, dirá Winston a un periodista cuando éste le pregunta por la atormentada relación que ha podido tener con su padre. 
De la primera entrevista, una conversación del padre de Winston con el editor de The Times, se deduce que, aun siendo un político conservador quiere adaptarse a la sociedad en la que vive y a los cambios en política y cultura. Justo al final del encuentro, el periodista le pregunta por la admiración que puede despertar en sus hijos. Sir Randolph contestará escuetamente: “Jamás se me pasó por la cabeza tal cosa”. De este modo se trasluce que en lo que más piensa es en su carrera, habiendo dedicado muy pocos esfuerzos a plantearse la educación de sus hijos.

La segunda entrevista, la de un periodista conversando con la madre de Winston (interpretada por Anne Bancroft), deja entrever las mentiras escondidas en la casa de los Churchill. Presenta a una madre aparentemente ideal y cuidadosa que es en realidad distante con su hijo. Una mujer infiel ante la perspectiva de un marido dedicado enteramente a la política. Un corazón devastado por la constatación de la infidelidad y demencia que ha llevado a su marido y familia a la ruina en todos los sentidos.

La tercera y última entrevista es al joven Winston. Se da durante la campaña previa a unas elecciones locales para las que ha presentado candidatura. El aplomo y la seguridad en sí mismo son sobresalientes, pero las preguntas del entrevistador hacen ver que no tiene muy claro porqué busca la política y el poder. ¿Es servicio a su país o la oportunidad para demostrar a su padre y a sí mismo que es alguien de provecho?

En el transcurso de esta última entrevista la película recoge lo que será uno de sus grandes dotes como líder: la oratoria. Ante la pregunta del periodista: “¿No cree que en los tiempos que corremos no hay lugar para jóvenes ricos en política?" Churchill responderá con un auténtico "elogio a la juventud”:

Creo en mí mismo. Creo en mi destino. (...) ¿Qué pretende, que me vean pero no me oigan? ¿Tendremos que ser siempre gobernados por viejos? ¿Acaso no han traicionado los viejos políticos todas las cosas maravillosas en las que creían cuando eran jóvenes? ¿Y al mismo tiempo no han traicionado a su patria? Creo que puede haber sitio para un hombre joven. Para muchos jóvenes en el Gobierno. Si pudiera les diría a todos los jóvenes del mundo entero: iEn marcha! Os necesitan ahora más que nunca. Sé que cometeréis errores, pero 
mientras seáis valientes y sinceros no podréis hacer daño al mundo. (Attemborough, 1972)

A partir de esta entrevista, ya en la segunda parte de la película, Winston regresa al servicio militar en campañas exteriores en India, Sudán y Sudáfrica, tras fracasar en el primer intento de acceder a la política. Su determinación y tesón están detrás de las peripecias que protagoniza en el campo de batalla. La suerte, el ingenio y su carácter aventurero, que a veces roza lo temerario, se alían en su famosa escapada de la prisión de los Bóers. El hecho acontece en 1899 mientras trabaja como corresponsal de la Guerra en Sudáfrica. Según las crónicas de El Imparcial en España y el The Morning Post británico, Winston Churchill habría escapado de un campo de prisioneros en Pretoria, recorriendo durante varios días unos 500 kilómetros sin apenas alimentarse, pasando oculto y logrando ser recibido en Durban como un héroe. Su relato fue muy difundido por toda Gran Bretaña, y la película lo recoge como paso decisivo para lograr su objetivo político. También le ayuda en su propósito la notoriedad que alcanza como escritor y columnista.

En definitiva, es en esta segunda parte del filme cuando en el joven Winston se advierten unas maneras que terminarán cristalizando en esos rasgos de carácter marcados en el futuro líder político. Por ejemplo, su determinación hacia el éxito; los matices sombríos en su forma de hablar que recuerdan a los de su padre; la tendencia al engreimiento que puede verse en su modo de insultar al maquinista en Sudáfrica por no hacer lo que le pide; su excentricidad, aunque por el momento se trate de detalles más ingenuos y juveniles. Todavía no estamos ante un Churchill fumador, errático y bebedor desde la mañana, pero se adivina su extravagancia al elegir un caballo blanco imposible de camuflar ante el enemigo, o al enfrentarse a peligros de muerte tan solo por obtener una medalla.

A su regreso del frente, con 26 años, logra su elección al Parlamento por el distrito de Oldham. Un año más tarde, en 1901, dará un speech parlamentario con el que resucitará la memoria de su padre y le hará justicia frente a la Cámara. Este hecho constituye el final de la película y "un principio”, como recita el propio personaje. Elocuentemente estas palabras del joven funden de 
nuevo a las imágenes de archivo de 1945, con Chuchill y su mujer junto a Jorge VI en el balcón de Buckingham Palace, donde es aclamado por el pueblo tras la victoria de la guerra. La película deja así claro que la historia de su niñez y juventud no tendrían valor de no ser la antesala de algo más grande.

En resumen, el Churchill de El joven Winston es un personaje rebelde, ambicioso y enérgico, que busca por encima de todo agradar la memoria de un padre al que admira y cuya veneración nunca fue correspondida. Es, en último término el retrato positivo de quien se ha enfrentado a dificultades desde niño y se ha hecho fuerte para llegar a ser más tarde un héroe de la historia.

\section{2. El instante más oscuro}

1901-1940. Este es el salto temporal en la vida de Winston Churchill que hay que dar para acceder al personaje de la película El instante más oscuro, en esta ocasión interpretado por Gary Oldman. Lejos del periodo de juventud e ideales, el filme muestra el carácter de Churchill en uno de los momentos más oscuros y determinantes de su carrera política, al tener que decidir continuar o la no su ofensiva contra Hitler, tras ser elegido primer ministro en mayo de 1940.

El guion de la película, firmado por Anthony McCarten7, encaja con la narrativa más común a los biopics políticos contemporáneos. Entre sus características está el centrar la vida del protagonista en un lapso de tiempo corto, incluso en un solo episodio que ilustre bien cómo es el líder y en qué ha consistido su liderazgo. Frente al largo periodo de vida que representa El joven Winston y que obliga a una estructura narrativa episódica, El instante más oscuro concentra la trama en los días que van del 10 de mayo al 4 de junio de 1940. Como ya se ha dicho, un momento decisivo para Gran Bretaña, Europa y, por supuesto, para el propio Churchill. La trama se apoya en tres de los discursos públicos de Churchill en este periodo: 'Blood Toil Tears Sweat' será pronunciado en la Cámara de los Comunes el 13 de mayo, 'Be Ye Men of Valour'

\footnotetext{
7 Anthony McCarten (Nueva Zelanda, 1961), novelista y dramaturgo y en los últimos años guionista. Entre sus trabajos destacan los biopics La teoría del todo (The Theory of Everything, Marsh, 2014), Bohemian Rhapsody (Singer, 2018) y Los dos Papas (The Two Popes, Meirelles, 2019).
} 
será emitido por radio el 19 de mayo, y finalmente 'We Shall Fight on the Beaches', una de sus intervenciones más famosas, que dirigirá Churchill el 4 junio en la Cámara de los Comunes tras la evacuación de Dunkerque. Este esquema sobre tres discursos ya anticipa una de las cualidades más destacadas de Churchill en la película: su oratoria y capacidad comunicativa, hasta el punto de que uno de los personajes dirá en los compases finales: "Winston Churchill ha convocado a la lengua inglesa a la guerra” (Wright, 2016).

La trama en sí tiene un poderoso conflicto en juego, que la hace incluso trepidante desde el punto de vista de la acción dramática. Se establece una contrarreloj clara, marcada por el avance de las tropas alemanas en Europa. En esos días caen Holanda, Bélgica y Luxemburgo y Hitler pone su vista sobre Francia, con idea de seguir después hacia Gran Bretaña. Además, la película recurre al intento por parte del ministro de Asuntos Exteriores, Lord Halifax, y del ex primer ministro, Lord Chamberlain, de negociar la paz del Reino Unido con Hitler para evitar así la caída del país. Ellos serán la fuerza antagonista interna contra la que deberá luchar Winston Churchill en sus primeros meses como primer ministro. En esta encrucijada hay otra figura clave, la del rey Jorge VI, que inicialmente mira con antipatía a Churchill por su excentricidad y la falta de cordura demostrada en otras ocasiones. Poco a poco su postura va cambiando a favor suya hasta otorgarle un apoyo incondicional que hace saltar por los aires una moción de censura que preparaban Halifax y Neville Chamberlain para derrotar a Churchill en el Parlamento.

En esta sucesión de hechos, bien documentada, el personaje de Churchill exhibe su férrea determinación de frenar a Hitler, aunque para ello tenga que hacer frente a su propio Gabinete de Guerra. Algunos de sus rasgos de líder, como su visión, inteligencia y coraje, quedan a la vista en este complot contra él. Como primer ministro toma la decisión de concentrar la batalla contra el ejército alemán en Calais, sacrificando a cuatro mil soldados británicos, para ganar tiempo y finalmente pone en marcha la operación Dinamo con la que espera poner a salvo a otros 300.000 soldados que esperan en Dunquerque. Elimina con esta maniobra el intento de negociación de condiciones de paz con 
Alemania que defienden Halifax y Chamberlain. Inmediatamente el Reino Unido entrará en la encarnizada batalla de Inglaterra.

Aunque pueda parecer lo contrario, sobre esta base de acción dramática se abre paso una historia principalmente centrada en el personaje y su caracterización. El filme de Joe Wright da una especial importancia a la dimensión emocional de los personajes. Se hace hincapié en los motivos que impulsan sus acciones y, en el caso de Churchill, se pone especial cuidado en equilibrar las luces y sombras de su personalidad. Para ello se superponen constantemente las esferas privada y pública del protagonista.

Mientras la esfera pública está dominada por hombres que obligan a Churchill a mostrar su lado más guerrero, valiéndole el apodo de "león"; en la esfera privada el carácter femenino es el verdadero protagonista. Son dos mujeres las principales confidentes de Churchill y, al fin y al cabo, quienes logran extraer lo mejor de él hasta reconducirlo, mejor dotado, a la arena política. Se trata, por un lado, de su mujer Clementine (Kristin Scott Thomas) y, por otro, de su secretaria personal en aquellos años: Elisabeth Nel (Lily James). Ambas son figuras clave para acercarnos a la personalidad de Churchill que el filme quiere subrayar. Hay varias licencias poéticas que la película toma con estos dos personajes, mezclando partes de ficción y de realidad.

El principal ejemplo está en la contratación de Nel como secretaria personal de Churchill, que significativamente se sitúa en el inicio del filme para terminar acompañando la trama hasta su final. En concreto, Churchill despide groseramente a Nel en su primer día de trabajo por no haber mecanografiado a doble espacio el texto que le ha dictado. Es una nimiedad que él considera de la máxima importancia. Sólo la intervención de su mujer Clementine salvará la situación. Ella corrige a su marido: “Querido, sabes que estás a punto de tener un tremendo poder, solo superado por el del Rey. Y con tanto poder deber debes ser más amable, y si es posible calmado... Quiero que todos te quieran y te respeten como yo" (Wright, 2016). Enseguida Elisabeth Nel vuelve a su trabajo y con su admiración hacia el primer ministro va aceptando su carácter inesperado y difícil, así como sus manías irracionales: su 
excentricidad, en otras palabras. Durante la trama, crece la confianza de Churchill hacia ella. El guion la hace protagonista del famoso signo de "victoria" con el que el primer ministro llenaba las fotos de la prensa y que llegaría a conformar todo un símbolo nacional durante la guerra. Más adelante, en otra secuencia inventada, Churchill confía a su secretaria información sobre la situación bélica, dándole acceso a estancias militares donde la presencia de una mujer no estaba siquiera permitida. Lo hace en un gesto de compasión y simpatía cuando ella le confiesa que tiene un hermano en el frente posiblemente muerto en combate. Nel tiene un papel de apoyo importante en la decisión de Churchill de poner fin a cualquier intento de negociación de la paz con Alemania. Y es ella también quien le ayuda a redactar su discurso final. Así, la presencia de Nel en el discurso del 4 de junio al final de la película y las miradas de complicidad que le dirige Churchill durante los silencios del speech, manifiestan el agradecimiento de este al trabajo de ella en la sombra.

Con el personaje de Nel, en definitiva, Churchill se presenta al público actual con una característica importante para un líder en nuestros días, como es la consideración hacia la mujer. Nel es un personaje creado para ser los ojos del espectador de hoy y dirigir su viaje emocional durante la película hasta el aplauso hacia un líder como Winston Churchill.

Por su parte, la figura de Clementine se encarga en el filme de recoger y transformar las inseguridades del primer ministro en cualidades. Ella le otorga desde el primer momento un apoyo incondicional. A través de la mujer de Churchill el espectador recibe el lado más vulnerable de Churchill, escondido bajo la apariencia de su determinación y seguridad: su mal humor, su falta de contención en los gastos domésticos, sus zozobras interiores, su tendencia a la depresión..., etc. Con Clementine salen a relucir aspectos que, si bien alejan a Churchill del pedestal, lo hacen a todas luces más humano y afín al común de los mortales de nuestro tiempo. Al igual que ocurre en otros biopics políticos contemporáneos, se presenta a Churchill como alguien que se enfrenta a problemas cotidianos muy similares a los de la audiencia (Frago \& Alfonso, 2017, p. 8). Gracias a esta cercanía, el espectador pasa por alto y comprende 
los defectos de un líder que cuenta con otras cualidades valiosas. No en balde, en una de las primeras escenas de la película, Clementine se encarga de recordar a Churchill cuáles son ante su inminente nombramiento como primer ministro:

- (Clementine): Muéstrales tus cualidades. Tu valentía...

- (Winston): ... Mi escaso juicio.

- (C): ...Tu falta de vanidad.

- (W): ... Mi voluntad de hierro.

- (C) (bromista): ...Tu sentido del humor. (Wright, 2016)

La conversación es una anticipación dramática a lo que el filme subrayará durante la trama.

Por último, aún debemos señalar a otro personaje colectivo anónimo que está presente en El instante más oscuro y que resulta otra vía más de caracterización del personaje. Se trata de "el pueblo británico", protagonista en dos escenas inventadas del filme. En una de ellas, en el primer cuarto de la película, se nos muestra cómo Churchill observa con atención, de camino a Buckingham Palace, la vida de los que no pertenecen a su clase social. Confiesa con sencillez a su chófer que no sabe hacer ni un huevo frito y que nunca ha cogido el metro. Estos pequeños gestos hacen que para el espectador Churchill se convierta en un político comprometido con los más débiles y desfavorecidos, a pesar de pertenecer a una clase de privilegiados. Este acercamiento a la voluntad popular alcanza su máximo exponente en una de las últimas secuencias, cuando Churchill decide no ir a una reunión en la que se juega el destino de Gran Bretaña en la guerra para tomar el metro por primera vez. Allí dialoga con la gente de a pie y toma nota de su ardor patriótico y su rechazo a la capitulación de Gran Bretaña ante Hitler. Con esta escena algo forzada por parte del guionista- se busca dar voz a la nación en lo que será la misión más crucial de Churchill en esos días de 1940: convencer al Parlamento de que lo mejor para todos es continuar contra Hitler.

Al final, como resultado de introducir en la película las dos voces femeninas y el personaje colectivo del pueblo británico, se dibuja a un líder con rasgos que conectan con la sensibilidad del público actual. El líder político de nuestros 
días es, de acuerdo con Kenny y Pearce, aquel que siente nuestro dolor, habla nuestro propio lenguaje y responde de inmediato a nuestros cambios de opinión (2014, p. 124). Es alguien que toma una carga pesada siendo una persona corriente $\mathrm{y}$, entre sus virtudes cívicas, destacan la tolerancia, la apertura al consejo externo, la capacidad de diálogo para lograr el consenso, la empatía y la inteligencia emocional (Frago y Alfonso, p. 8).

El instante más oscuro, en definitiva, acerca a la audiencia a un líder político que, si bien no es superior al ciudadano de a pie en muchos aspectos, en un momento crucial de la historia de Europa es capaz de dirigir a su pueblo hacia lo más conveniente, con voluntad de hierro, “como un león”.

\section{Un líder europeo. Conclusiones}

Tal y como se ha tratado de mostrar en los análisis de estas dos películas, el personaje de Winston Churchill se dibuja como un líder político idóneo no solo para el tiempo en que vivió sino también para la época en que se estrena cada filme. Es preciso recordar que ambos títulos proyectan a Churchill hacia el mismo año y acontecimiento: 8 de mayo de 1945, día de la Victoria, momento de la capitulación de la Alemania nazi y el cese de la Segunda Guerra Mundial. Sin este hecho, Churchill dejaría de ser el líder de carácter legendario que conocemos. Por el contrario, lo convierte en líder europeo y no exclusivamente británico, al nacer entonces la futura Europa democrática vigente hoy. Es conocida la proclama de Churchill, posterior a la guerra, de crear "una Europa unida y pacífica, una especie de Estados Unidos de Europa” (Discurso en la Universidad de Zurich, 1946), así como su propuesta un año después en La Haya de crear un Consejo de Europa y atisbar también la idea de un futuro tribunal europeo.

Pese a no estar el Reino Unido entre los primeros países de la Unión, el "sueño europeo" no se hubiera fraguado sin la participación de Winston Churchill como figura clave en el correr de los acontecimientos. Atendiendo a su papel de "padre fundador" de la Unión Europea, señalamos que se produce una coincidencia al menos sugerente en el estreno de las dos películas analizadas 
en este trabajo. La figura juvenil de Churchill en la película El joven Churchill coincide con un momento en el que Gran Bretaña está a punto de incorporarse a la Unión Europea (lo hará un año más tarde, en 1973, junto con Irlanda y Dinamarca). El símbolo de promesa y futuro que acompaña a Churchill en el filme también puede proyectarse sobre este próximo acontecimiento. En sentido opuesto, la película El instante más oscuro se estrena cuando el Reino Unido ha votado a favor del Brexit y está en negociaciones para su salida de la UE. Sobre esta circunstancia, también resulta evocadora la imagen nostálgica del líder.

Independientemente de lo que haya de interpretación en este último punto, sí puede afirmarse que tanto El joven Churchill como El instante más oscuro son películas enmarcadas en dos periodos convulsos para Europa, donde el liderazgo positivo de Churchill ilumina un cuadro con abundantes sombras. Las virtudes con las que se adorna al protagonista en cada película coinciden con los rasgos más valorados por la sociedad del momento. Por ejemplo, la determinación y el coraje del joven Churchill en la película de Attemborough; y la experiencia y la visión en el Churchill que se enfrenta a la II Guerra Mundial en el filme de Joe Wright. Asimismo, los defectos que cada filme destaca sobre Churchill son aquellos que el público de 1972 y de 2016 tiende fácilmente a perdonar. Es el caso de la rebeldía y la ambición, en El joven Churchill; o las destemplanzas y la inseguridad / necesidad de afecto en $E l$ instante más oscuro. Lo que no discute, en ninguno de los filmes, es su liderazgo político, que permanece incólume y reafirma a Winston Churchill como todo un referente para el mundo democrático.

\section{Referencias bibliográficas}

Attemborough, R. (1972). Young Winston. UK: Praesens-Film.

Bingham, D. (2010). Whose Lives Are They Anyway? The Biopic as Contemporary Film Genre. New Brunswick, NJ: Rutgers University Press.

Bishop. Michael F. (2018). Churchill on Screen: the Five Best. Finest Hour, 1 (179): 8-11. 
Campbell, J. (1949). The hero with a thousand faces. Princeton: Bollingen Series.

Cerny, P. G. (2010). Afterword: The New Pessimism in Twenty-First Century World Politics. En T. Stevens, \& N. Michelsen (eds). Pessimism in International Relations. Provocations, Possibilities, Politics. Londres: Palgrave.

Chapman, J. (2005). Past and Present: National Identity and the British Historical Film. Londres: Tauris.

Churchill, W. (1930, ed. 2012). My early life. Londres: Eland.

Ferro, Marc. (2008). El cine: una visión de la historia. Madrid: Akal.

Frago, M. \& Alfonso, A. (2017). 2008-2013 Political Biopics: Adapting Leaders for a Time of Crisis. Javnost the Public 1 (24), 1-14. DOI: $10.1080 / 13183222.2017 .1275162$

González-Requena, J. (2006). Clásico, Manierista, Postclásico. Los modos del relato en el cine de Hollywood. Valladolid: Castilla Ediciones.

Jenkins, R. (2002). Churchill. Barcelona: Península.

Landy, M. (1991). British Genres. Cinema and Society: 1930-196o. Princeton, NJ: Princeton University Press.

Landy, M. (2001). The historical film: History and memory in media. New Brundswick, NJ: Rutgers University Press.

Marin Pedreño, H. (2018). Mayo del 68: días de Júpiter. Arbor, 194 (787), a434. https://doi.org/10.3989/arbor.2018.787n1007

Marwick, A. (2000). Introduction: Locating Key Text Amid the Distinctive Landscape of the Sixties. En A. Aldgate, J. Chapman \& A. Marwick (eds.). Windows on the Sixties. Exploring Key Text of Media and Culture. Londres: I. B. Tauris, xi-xxi.

Marwick, A. (2006). Youth Culture and the Cultural Revolution of the long Sixties. En A. Schidt \& D. Siegfried (eds.). Between Marx and CocaCola. Youth Cultures in Changing European Societies, 1960-1980. Oxford (UK): Berghagn Books, 39-58.

Morgan, I. W. (2011). Presidents in the Movies: American History and Politics on Screen. Nueva York: Palgrave McMillan.

Kenny, M. y Pearce, N. (2014). Political Leadership in an Anti-Political Age. Juncture 21 (2), 122-130. https://doi.org/10.1111/j.20505876.2014.00791.x

Pérez López, P. (2018). Mayo del 68: historia y legado. Cincuenta años de la revolución final. Nuestro Tiempo 698, 104-111.

Pennacchia, M. (2016). Culturally British Bio(e)pics: From Elisabeth to The King's Speech. En M. Minier \& M. Pennacchia (eds). Adaptation, Intermediality and the British Celebrity Biopic. Nueva York: Routledge, 33-50. 
Roberts, A. (2018). Churchill: Walking with destiny. Nueva York: Viking.

Rodríguez Sáez, A. (2018). El populismo: de intruso a problema relevante para la ciencia social. Revista Internacional de Sociología, 76 (4), e114. DOI: $\underline{10.3989 / \text { ris.2018.76.4.18.076 }}$

Rosenstone, R. (2006). History on Film / Film on History. Londres: Longman Pearson.

Scott, I. (2011). American Politics in Hollywood Film. Edimburgo: Edinburgh University Press.

Toplin, R. B. (1996). History by Hollywood: The Use and Abuse of the American Past. Urbana: University of Illinois Press.

Toplin, R. B. (2002). Reel History: In Defense of Hollywood. Lawrence: University Press of Kansas.

Vidal, B. (2014). The Biopic and Its Critical Contexts. En T. Brown \& B. Vidal. The Biopic in Contemporary Film Culture. London: Routledge, 1-32.

Wright, J. (2017). Darkest Hour. USA y UK: Working Title Films / PWPIC.

Zurro, J. (2018). "El cine se rinde a Winston Churchill", El Español, 11 de enero de 2018. https://www.elespanol.com/cultura/cine/20180111/noquedan-lideres-cine-rinde-winston-churchill/276473054_o.html 